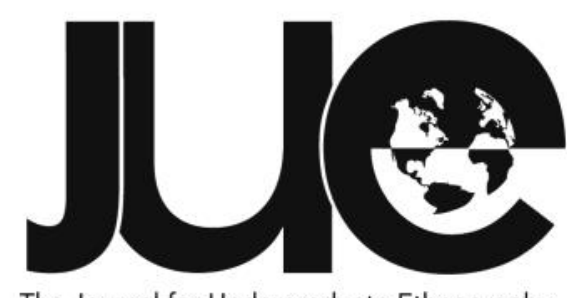

The Journal for Undergraduate Ethnography

\title{
Visible, Invisible: A Portrait of the Intersection Between Whiteness and Moroccanness in the Netherlands
} Oliver Dougherty

Maastricht University, oliver.a.dougherty@gmail.com

\section{ABSTRACT}

This article explores the influence of appearance on experiences of race and racism in the Netherlands. It is based on one semistructured, in-depth interview with a 20 year-old performing arts student who, despite his outward appearance of being white, has Moroccan heritage. The intersection between whiteness and Moroccan identity in the case of the interviewee is considered in terms of the Dutch national image, racial passing and Dutch visual culture. The results of the in-depth interview provide insight into the exclusivity of the categories of white and Moroccan in the image of Dutch identity, as well as the claims to a post-race Netherlands.

Keywords: whiteness, racial passing, racism, ethnic minority, minority-privileged identity, visual culture 
"I am just a guy from the Hague" -- Najib, the interviewee of my research.

F rom this quotation, what is the physical image that would be expected of Najib? If I were to ask a Dutch person to respond, I can imagine a number of qualities that may be mentioned in the dominant image: tall, blonde hair and blue eyes, for example. However, while probably not explicitly named, one quality that is akin to these characteristics would emerge as implicit: whiteness. Indeed, from the discourse of belonging examined by Essed \& Trienekens (2008) that illustrated a stunted welcome of people of color into the Netherlands, they have concluded that whiteness is implicitly pictured as essential to the image of Dutch identity. Whiteness, therefore, becomes a category that excludes cultures and nationalities that are imagined as non-white in the Netherlands, particularly in ethnic minorities. In this sense, the Dutch and ethnic minorities become placed in a binary as two irreconcilable categories that are racialized as white and non-white, which problematizes and provides a lack of space for the acknowledgment of identities that occupy both positions (Essed \& Trienekens 2008). In turn, two elements may be surprising for the average (white) Dutch person to learn in regard to this quotation: firstly, that it is from someone with Moroccan heritage and, secondly, that he fits within the aforementioned dominant white image.

While culturalist arguments may claim to reject biological determinism, the probable confusion at learning of the impossible intersection between whiteness and Moroccanness in the case of the interviewee hints at an internalized understanding of race in the Netherlands that is unconsciously dependent upon the visible (Siebers \& Denissen 2015). In fact, according to Dienke
Hondius' (2014) Black Dutch Voices: Reports from a Country that leaves Racism Unchallenged, discourse of race in terms of skin color is specifically avoided: the Dutch "don't do" race, implying that the country is in fact "post-race". Despite the perceived irrelevance of skin color, however, her corroboration of 72 interviews with people living in the Netherlands of Afro-Caribbean descent reveals that their appearance most often formed the basis of and therefore largely determined their experiences of racism. As such, skin color and appearance are crucial to the experiences of racism in the Netherlands. In light of the visible foundation of race in the Netherlands explored by Hondius (2014), my research has investigated the following question: How does appearance influence experiences of race and racism in the Netherlands?

The problematic nature of appearance in racialized discourse of culture and ethnicity surfaces in specific identities in the Netherlands. To explore the intricacies of one such identity, I conducted an in-depth, semistructured interview with Najib (not his real name). Najib is a 20-year-old performing arts student who was born and raised in The Hague. Despite an Arabic name and Moroccan heritage from his mother, Najib visually appears to be, and considers himself, a white Dutch man and indeed "just a guy from The Hague". The comprehension, negotiation and re-negotiation of Najib's racial identity both by himself as well as by wider Dutch society, can be positioned within discourse (or lack thereof) of race in the Netherlands. The understanding and explanation of Najib's impossible racial identity in a supposedly "post-race" Netherlands will therefore be the aim of my research, and will be discussed within this paper in terms of the Dutch national image, racial passing and Dutch visual culture. Firstly, however, it is important to establish a definition of race in the contemporary context of the Netherlands. 


\section{Defining Race}

It should be noted that this research is informed by a definition of race from a critical whiteness studies perspective. In particular, Robin DiAngelo (2012) considers race to be a system of unequal power between white people and people of color in terms of history, culture and institutions. Such a definition moves beyond the consideration of only isolated acts of racism, understanding it instead as a broader system into which all of society is interwoven and which is fundamentally defined by the multi-layered dominance of white people. It is among this broader system of race that Najib's navigation of his whiteness shall be interpreted.

The process of racialization should be considered when focusing on race in the context of the Netherlands. While the concept of race is largely borne out of efforts by nineteenth century Western biologists and anthropologists to establish an order of racial categories which saw Caucasians labelled as superior and which functioned to justify colonialism, ongoing processes of "Othering" have transformed the concept to suit a contemporary context (Essed, 1996). In fact, race has in recent years been implicit in discussions of culture and ethnicity, particularly in the rise of migrant-hostile discourse and dynamics in Western Europe, including in the Netherlands (Essed \& Trienekens, 2006). Importantly, migrant-hostile discourse depends on a target not defined by a racial category, but rather by one that is, for example, religious, national or cultural. Nevertheless, such discourse maintains qualities which are reminiscent of racism connected to colonial history.

Essed (2006) suggests the term 'racial-ethnic' to account for the convergence of racialization and ethnicization in the Netherlands. She notes two particular national groups - Turks and Moroccans - who migrated to the Netherlands in the 1980's in the context of post-war migration policies and economic crisis and parallels their subordinate image and treatment in the Netherlands to those of the Surinamese, who are from a former Dutch colony. In essence, she recognizes that groups that are tied together by concepts such as nationality, migrant status or religion may be racialized such that they experience a form of racism that both departs from and is intricately related to that which was fabricated by nineteenth century Western sciences. Although it is a useful heuristic in understanding a contemporary form of racism, the term 'racialethnic' shall not be employed throughout this ethnographic portrait, as the confounding of concepts such as culture with race shall be discussed more specifically. Nevertheless, in terms of Najib's navigation of his racial identity, what is important to underline is that while Moroccans are a national group, they have become racialized because of their specific history in the Netherlands which thereby distinguishes them from the broader and perhaps more traditional racial category of North Africans.

\section{Limitations}

With a sample size of one, it is important to reflect upon the limitations of my research. In fact, it is not possible to draw broad conclusions about the mechanisms of race in the Netherlands from one sole interview. However, this does not imply that this research is irrelevant for Dutch critical race studies. Instead, rather than to generalize, the aim of this research is to provide insight into the operation of appearance in the experiences of race and racism in the Netherlands in corroboration with previous research, particularly that of Hondius (2014). In fact, one point which the ethnographic portrait format of this study illuminates is that external validity emerges in qualitative research not through generalizability, but rather transferability. Indeed, an ethnographic portrait may exhibit significant transferability when the findings are rich and detailed enough to be transferable to other settings. One notable example is Paloma Gay y Blasco's The Fragility of Cosmopolitanism: A Biographical Approach (2010) which ethnographically analyses the position of Agata, a Gitano woman from Spain who fled her abusive husband and now lives in a 
multicultural setting with her Moroccan lover. In this ethnographic portrait, the presence of a singular research subject is not a drawback but rather a strength; it is the subjective, uncommon and unique qualities of Agata's lived experiences and identity which position her in an insightful standpoint that allows for rich findings and thus transferability. With the valuable standpoint of Najib in mind, it is clear that an ethnographic portrait focusing on his lived experiences and opinions may likewise render the findings significantly transferable to other settings.

As such, while the research of Hondius (2014) provides an extensive and comprehensive overview of racism in the Netherlands in terms of its visible foundation, there is also value in a single portrait of racial experience, particularly when the subject occupies a uniquely insightful standpoint. Indeed, the portrait of Najib provides one indepth exploration of the subjective and lived experience of race and racism in the Netherlands from the valuable perspective of a minority-privileged identity; that is, Najib is a minority because of his Moroccan heritage, but privileged because of his whiteness. Furthermore, Hondius (2014) argues that while racism is framed by mainstream Dutch ideas purely as blatant and discrete acts, it more commonly appears in passive forms which are nonetheless significantly more difficult to research because of their seemingly undetectable nature. In particularly, in the Dutch context, Hondius (in Essed \& Hoving 2014) distinguishes between passive tolerance and passive intolerance; the allowance of space for cultural Others to engage in traditions and customs as opposed to the rejection of these practices without discussion around their particularities respectively. Nevertheless, she argues that passive tolerance and passive intolerance are rather similar because both function to reject discussion around cultural differences that thereby reinforces them as essential, irreconcilable and definitive. In fact, it is the suppression of action around issues of cultural difference for mainstream Dutch society that defines these forms of (in)tolerance as passive. In this sense, forms of passive (in) tolerance produce a somewhat concealed racism, which allows the Netherlands to make claims to their supposedly "post-race" state. Therefore, a portrait of Najib's particular subjective experience is significant considering his embodiment of the "impossible" intersection between whiteness and Moroccanness. This information may thus act as a gateway into research of these more passive mechanisms of racism in the Netherlands that are connected to the fabrication of a "post-race" country. In fact, Najib's hybrid racial identity materializes the precisely inessential, reconcilable and indefinitive nature of the cultural differences between Dutch and Moroccans people, and thus undoes notions of passive tolerance and intolerance merely through his existence. Ultimately, while generalizations cannot be drawn solely from the ethnographic portrait of Najib, the analysis of his subjective experiences may extend upon insight into certain mechanisms of race in the Netherlands in terms of visible appearance that extend from the research of Hondius (2014) and contribute to its transferability to other settings.

When attempting to understand the location of Najib's racial identity, my own subjective position should be considered. Notably, I am a white Australian male whose Dutch is quite poor which limits my intrinsic knowledge of Najib's identity. This limited position in my research gives rise to a number of prejudices which I cannot avoid. However, there is value in having an outsider's perspective. Indeed, having been raised in a society in which the discourse of race is more salient than in the Netherlands, I have perhaps been enabled to make more nuanced claims about racism than the average Dutch person. In any case, I have aimed to maintain as much credibility (Guba \&Lincoln 1981) as possible when connecting my claims with Najib's opinions.

\section{"The Moroccans on the Corner of the Street": The Dutch (National) Image as White and not Moroccan}

The Dutch national image has two key qualities: liberalism and tolerance (Weiner 2014). The 
essential position of these qualities in the Dutch national image has given rise to the post-racial model that posits that race hierarchies and conflict have disappeared at the meta-level that is, in terms of overarching societal morals and values - and therefore that society should move towards colorblind discourse that focuses on individualism (Sundquist 2012). As such, this image allows the Netherlands to picture itself as a nation that is fundamentally not racist. More specifically, in line with this national image, race is framed in the Netherlands as a false sense of hierarchy based on biological determinism, which therefore places racism as limited to the far-right or far in the past (Lentin 2008). Such a framing of race has contributed to Hondius' (2014) claim to the lack of racial discourse in the Netherlands, since the consistent perpetration of racism outside of the dominant Dutch image means that the topic supposedly does not deserve significant attention. Moreover, the encouragement of a colorblind attitude towards race relations inherently overlooks the integrally white characteristic of Dutch identity. Indeed, because the language of race is suppressed in the postrace era, the identification and discussion of the essential whiteness in the Dutch national image becomes problematic. As I will demonstrate, these issues clearly come to surface in the case of Najib.

The incongruence between Najib's Moroccan heritage and appearance produces an experience of whiteness that is uniquely different from the image of Dutch identity. Discourse of a post-race Netherlands has interacted with his treatment by other white Dutch people to influence his own self-concept. Najib made it clear from the beginning of the interview that he conceived himself as a white Dutch person, describing himself as "just the guy with blonde hair and blue eyes from the Netherlands". As such, his Moroccan heritage is concealed in his own self-concept. This selfconcept emerges within a context in which many linguistic limitations of mixed ethnic identity in the Netherlands exist. Indeed, although Najib embodies a racially hybrid identity, Dutch terminology of ethnic identity problematizes and makes it difficult to define oneself as a hybrid; the label of DutchMoroccan, for example, is not easily accepted by Dutch language and society (Weiner 2014). These linguistic facets may inform part of Najib's self-description as totally Dutch with the effect of conforming him to the dominant national image.

In essence, the Dutch image can be seen to be structured and interacting with Najib in such a way that he is led to minimize his Moroccan identity. However, this minimization of his Moroccan heritage is also prompted by the visual markers of race that present him as Dutch; that is, primarily, his whiteness. Indeed, when asked how Dutch society may encourage him to distance himself from his Moroccan background, Najib explained that "it is not pulled out of me. The Moroccan side is not stimulated, but I think that is also a consequence of me not visually being my Moroccan side". Here, Najib explains that one reason why Dutch society and its citizens do not bring out his Moroccan side stems from the fact that his appearance cooperates with the white Dutch image and not the image of a Moroccan man. With whiteness acting as a visual marker which communicates to others about Najib's race and identity, it may be considered a performance in a Goffmanian sense. In fact, Goffman (1959) conceives of a performance as all aspects of an individual that are presented to and influence others. By performing whiteness, therefore, Najib communicates his position in the white Dutch image.

In fact, this image is well illustrated by the Dutch linguistic dichotomy of autochthone and allochthone. Typically, the former refers to indigenous, real and authentic Dutch while the latter is the opposite form; the foreigner, the problematic, the not-quite-Dutch and, therefore, the second-class citizen (Essed \& Trienekens 2008). Although the demarcation between these two categories is promoted as one that is cultural and ethnic, implicit within is also the similar dichotomy of white and nonwhite respectively (Essed \& Trienekens 2008). Indeed, skin color is a marker of belonging, and positions individuals within the autochthone/ allochthone binary. For Najib, therefore, 
because he appears to be and performs himself as white, he is consistently referred to as Dutch which strengthens his autochthonous location. As a result, while distinctions between autochthone and allochthone are explicitly labelled as based on culture and ethnicity, they embody that which Mica Pollock (2004) would describe as color muteness. That is, they in fact legitimate the articulation of clear racial hierarchies in a supposedly "post-race" Netherlands by providing a language that is not race or color explicit, yet fulfills the same agenda. Finally, it is important to note that by engaging in a program of color muteness that reinforces the supposedly irreconcilable nature of cultural differences, the autochthone/ allochthone binary in which Najib is embedded promotes passive forms of (in)tolerance.

Because of his white appearance, Najib responds quite uniquely to negative stereotypes of and racism towards Moroccans in the Netherlands. According to Gregory Stone (1974), appearance is intricately interwoven into the construction and mobilization of the self. Using the metaphor of clothing, he explains that the self is both dressed by an individual and addressed towards others through their appearance. In fact, the self is constituted by the alignment between the identifications of an individual by herself and others; that is, when the individual and the other attach the same meanings to the former's appearance, the self is produced. Stone's (1974) conception of the relationship between appearance and the self is reflected in Najib's feeling of distance to the negative stereotypes of Moroccans. Najib emphasized one stereotype in particularly, which he referred to as: "The Moroccans on the corner of the street." Indeed, Najib claims that the negative stereotypes of Moroccans, such as this one, do not implicate him because of his outward appearance as a white Dutch person. In essence, the self that is produced by his appearance defines Najib as a white Dutch person and thus establishes a discrepancy between the visual image of Moroccans and his own self, with the effect that the negative stereotypes become personally irrelevant. However, these negative stereotypes prove to produce internal feelings of discomfort when reflecting on his mother's family:

During my holidays in Casablanca I met my nephew and grew a strong relationship with him... The guys that are called in these situations "the Moroccans on the corner of the street" really do look like my nephew. So sometimes I stop and notice that they are talking about guys who look exactly like my nephew who I had a great time with and have a great bond with.

As such, Najib becomes affected by racist stereotypes of Moroccans by the connection to his family. Here, the stereotype of "the Moroccans on the corner of the street" relies on an expression of cultural differences akin to the category of allochthone. "The corner of the street" acts as a passively intolerated space which is literally outcast from Dutch society and the Dutch image, as if Moroccan culture cannot fit therein. Underneath the guise of culture, Najib's response to the stereotypes of Moroccans reveals them to be dependent on biological forms of racism as he is shown to have an internalized sense of racial categories that is based on skin color. While the self that is produced by Najib's appearance defines him as white and Dutch, that of his nephew emerges as Moroccan and therefore it is his family and not his whiteness that becomes the link to his negative response to racism towards Moroccans.

Siebers \& Dennissen (2015) dismiss the "racism-disguised-as-culture" argument on the grounds that it is problematic for researchers and scholars to uncover racism if it is entirely hidden by notions of culture. They question whether biology-based racism may be inferred if only discourse of cultural incompatibility is detectable. However, Najib's lived experience conflicts with the visually deterministic nature of racial categories that is prevalent in Dutch society. That is, his whiteness does not allow him to feel his self-concept to be affected by the racist stereotypes towards Moroccans, yet his family heritage - which is implicit in his racial identity - achieves this exact end. If the image of "the Moroccans on the corner of the 
street" was borne out of culture, then how can the visual congruence between this stereotype and Najib's nephew be the foundation for his feelings of discomfort? The only answer can be that biologically-based racism is implicit in discourse of cultural incompatibility; Najib's lived experience therefore supports the "racism -disguised-as-culture" argument.

In any case, what is clear from Najib's relation to the "Moroccans on the corner of the street" stereotype is a simultaneous sense of distance and proximity to both his whiteness/ Dutchness as well as his Moroccanness. It appears that the fluid and unconventional relationship to his racial identity positions Najib within that which Homi Bhabha (in Bolatagici 2004) would label the "third space". The third space represents a site of translation and negotiation of cultural ties into one's hybrid identity, while undermining discourse of cultural and racial polarity. The process of negotiation became clear in the case of Najib when he articulated the intangible benefits of his mixed racial background: "I think it would be a waste to be one thing - to be just Dutch, or be just a Dutch guy. I think it would be a waste to choose one if you can eat from both sides." Here, by articulating the perceived notion of waste associated with being merely "one thing", Najib engages in the process of negotiation that illuminates his position within the hybrid third space. Furthermore, the benefits of "eating from both sides" illustrate the third space as a site that is transgressive in a positive sense in a similar manner to its conceptualization by Bolatagici (2004). In her opinion, the transgressive qualities of the third space become distinctly positive through their deconstruction of the rigidity of racial categories as well as the concept of race itself. This is achieved precisely because the third space locates the wholeness of hybrid identities not in the bricolage of its origins, but in the transformations borne out of elements within this space; the acts of unification and organization involved in "eating from both sides".

Indeed, while forms of passive (in)tolerance in the Netherlands juxtapose white Dutch and non-white Others based on their cultural differences, the unification of these supposedly irreconcilable categories within the third space inherently undermines these divisive conceptions of race and racism. As such, when returning to Najib's relation to the aforementioned negative stereotype of Moroccans, the personal process of negotiation involved in his position within the third space allows him to undermine its racist foundation. Indeed, one of his critiques of the Moroccan stereotype was that "there are also white guys standing on the corner of the street." Departing from this critique, despite the process of socialization in Dutch society that functions to define Najib as white based on his appearance, his position within the third space grants him an acute understanding of the negative stereotypes of Moroccans. In effect, the exact power of Najib's hybrid identity is his unique position within the third space which allows him to undermine the authority of dominant ideas of race and destabilize the notion of a "post-race" Netherlands itself. Indeed, notions of passive (in)tolerance which reinforce cultural difference between Dutch and Moroccan become unified and therefore undone simply by the existence of Najib's minority-privileged hybrid identity.

Although his whiteness has socialized Najib to believe racism towards Moroccans has no influence on his self-concept, his discomforting experiences of racism emerge via the visual markers that connect his family to images of "the Moroccans on the corner of the street" and therefore position him within the third space. While these negative stereotypes are presented under the guise of cultural terms, since it is his personal connection to whiteness that socializes Najib into distancing himself from them, they may be demonstrated to serve to conceal the biologically deterministic foundation on which they stand; Dutch as white and Moroccans as non-white. The intersection between Moroccan and white is rejected by the Dutch national image and forms of passive (in) tolerance which therefore renders Najib's hybrid identity as impossible. In any case, Najib's fluid process of negotiation and selfunification in the third space allows the subversion of these dominant ideas of race and racism in the Netherlands. 


\section{(Almost) Passing (Post-)Racial Boundaries}

Negative stereotypes may be understood as products of the stigma of group identity that surround Moroccan people in the Netherlands. In fact, Erving Goffman (1974) claims that the means by which one's possession of a certain stigma is communicated to others is through visibility. Whether or not the possession of a stigma is visible to others defines how one may experience the negative consequences of such a stigma. In terms of the visibility of Najib's race, the intersection between white and Moroccan allows for a case in which his Moroccan heritage is often concealed by his visible appearance. In this sense, because the visible appearance of Najib as white conceals his possession of his stigma, he gains the advantage of being considered "normal" and thus not Moroccan and not stigmatized.

Nevertheless, although Najib passes as a white Dutch person in most situations, there are cases in which his Moroccan heritage becomes distinctly visible. The most salient of these examples noted by Najib were "with my Moroccan family, when I talk about Morocco or when I don't judge so fast "those Moroccans on the corner of the street." Here, Najib positions the visibility of his Moroccan heritage precisely in his own actions. Such an understanding of the appearance of Moroccan identity points towards the distinction made by Goffman (1974) that visibility is not necessarily defined by visual markers, but rather by what is noticeable or evident. In the case of Najib, Goffman (1974) may claim that it is through his actions that his Moroccan identity continues to "cast a shadow" (p.94) even though it is visually imperceptible. As such, race becomes a performance that allows Najib to reveal his Moroccan heritage in some instances and not in others (Sundquist 2010; Goffman 1959).

Najib's capacity to choose to reveal his Moroccan background uncovers his possession of that which Waters (1996) would describe as a symbolic or optional ethnicity. According to Waters (1974), in the context of the USA, whiteness grants to individuals the possession of a family heritage that is without significant social cost to their lives and thus has merely a symbolic impact. This contrasts to the lived realities of people of color who cannot avoid experiencing racial oppression on both everyday and systemic levels because of their skin color. For Najib, his hybrid identity is concealed by the fact that he visibly appears white and therefore he is granted the privilege of choice; that is, the choice to decide for himself the instances in which his Moroccan heritage is revealed.

In essence, Najib's possession of an optional ethnicity is encompassed by his ability to pass as white. In terms of the passive forms of (in) tolerance in the Netherlands, the supposedly essential racial categories that are marked by cultural difference propose that one cannot sit in both the categories of white and Moroccan. As such, Najib finds himself in a position produced by Dutch society in which he must move towards, and indeed pass as, one category or the other. Passing is significant as it reveals the socially constructed nature of racial categories and demands recognition of the notion that identities are "processual, intersubjective and contested/contestable" since they depend upon the repetition of embodied actions (Jackson and Jones in Elam 2007, p.750). Moreover, Goffman (1974) argues that passing allows one to avoid their stigma and to effectively obtain the advantages of being considered "normal". Therefore, significant to the undermining of the "postrace" claims of the Netherlands are the benefits of transgressing racial boundaries via passing into categories which are labelled as "normal".

In contrast to the advantages gained when one is considered "normal", the act of passing also shines light on the disadvantages associated with stigmatized categories. Indeed, the disadvantages of being Moroccan can be escaped by Najib because his appearance produces an optional ethnicity and thus the capacity to pass as white:

I'm in a too easy situation of having Moroccan heritage because you don't see it and I could deny it... There are people in my class who 
can't go around it because you see it and you can't cancel the disadvantages. Maybe they have a lot of disadvantages and I rarely ever have disadvantages, so that's maybe my luxury position.

Despite Najib's privilege to pass, in the case of the other students in his class "who can't go around it" their skin color acts as a visual marker that inextricably connects them to their non-white racial identity. In contrast to Najib's aforementioned actions which "cast a shadow" of his Moroccan identity, the skin color and appearance of people of color in his class means that their stigma is blatant and unavoidable and thus they are unable to pass: in effect, they become unavoidably subject to forms of passive (in)tolerance. Goffman (1974) employs the term visibility to refer to the perceptibility of one's stigma to others, which is therefore not only restricted to sight. However, he does indeed underline sight as the mechanism that renders stigma most visible to others, which is therefore reinforced by the imbalances between Najib and people of color in his class that stem from the outward (in) obviousness of their stigma. Using the example of ugliness, he explains that such a visually visible stigma produces its prime effect in social situations. In this sense, like ugliness, Goffman (1974) may consider that visible features stereotyped as being Moroccan transform Moroccan identity into a stigma that is focused on social situations in the Netherlands, rather than Najib's aforementioned actions which refrain from having any initial social impact.

In contrast to the optional ethnicity granted to white people, it is likewise useful here to reflect upon Franz Fanon's The Fact of Blackness (1967) in terms of the implications of non-white visual appearance. Fanon (1967) argues that Black identity operates like an inevitable social uniform. Indeed, Blackness is relationally dependent upon white people and cannot be avoided because it is based on physical appearance; this, Fanon claims, is the very fact of Blackness. The fact of Blackness is the case for Najib's classmates who "can't go around it because you see it". However, it is not the reality for Najib who can pass as white because of the Goffmanian performative nature of his racial identity that is associated with his appearance. In any case, the mere possibility of passing as white disrupts claims to a post-race Netherlands. In effect, if the Netherlands were truly "post-race", Najib would gain no advantages by passing as white. Therefore, it is the precise possibility of Najib's racial passing that uncovers both inequalities between the experiences of white people and Moroccans in the Netherlands as well as the persistence of race and racism.

However, Najib's capacity to pass as white becomes problematic when considering the Arabic root of his name. According to Onwuachi -Willig and Barnes (2005), a name can represent a racial signpost that is connected to the negative connotations of skin color and race and thereby may elicit prejudice. Therefore, impressions of Najib based purely on his name exposes his minority ethnic identity, destabilizes the privilege he experiences from passing as white and thereby leaves him vulnerable to racial prejudice. In fact, Najib explained one particularly salient act of racism towards him that was caused by his name in an experience with his housing agency:

I had a complaint and I sent my name and they went to my house, but I wasn't there. They found my roommate and the man from the housing agency said "Where is Najib?" and he replied that I wasn't there...then I came in and wanted to go into my room and he said "Whoah, this is not your house" and I said "No, I'm Najib" and he said "Oh (nervous laugh), I thought you were going to be some big Black Moroccan guy!

In this instance, not only does the employee of the housing agency express his internalized racial profile of a Moroccan man based on Najib's name, he also makes a discomforting, ignorant and racist comment when reacting to his whiteness. When asked to consider why the man laughed, Najib explained: 
Maybe he was ashamed of not expecting that [I am white] and maybe he actually felt relief because of that, but I also expect that he was trying to cope with the situation that he just made himself a bit of a fool.

Indeed, the racist comment may simultaneously express shock, shame and relief in discovering that whiteness and Moroccan identity can overlap. Furthermore, to extend upon Najib's interpretation of the man's laughter as a coping mechanism, this action also seems to function to establish an expectation that Najib would join in the laughter and therefore direct the attention away from the racially engrained notion of cultural difference embodied by the man. In fact, Najib experiences discomfort in an expectation that would effectively require him to ignore his internalized racial profile because he visibly appears to be in line with the white Dutch image. This expectation illustrates that which Robin DiAngelo (2012) labels white solidarity; the inherent agreement between white people to not challenge or compromise the comfort of one another when racism emerges, thereby maintaining white privilege and white supremacy.

Moreover, in a Goffmanian sense, the expectation of white solidarity on behalf of the housing agent may motivate Najib to cover the stigma of Moroccan identity (Goffman 1974). Acts of covering reduce the negative consequences of stigma, in contrast to passing wherein it is concealed (Goffman 1974). In addition, covering functions to draw attention away from the stigma itself while simultaneously focusing the social interaction more directly on its official content (Goffman 1974). Therefore, such a situation, which may motivate Najib to cover his Moroccan stigma, operates as an attempt by the housing agent to refocus the social interaction to the housing complaint itself. Importantly, since the laughter ultimately attempts to avoid the sense of cultural difference engrained in the housing agent's racial profile of a Moroccan man, it embodies the form of passive tolerance that is distinctive of Dutch racism. Najib, in fact, experiences this expectation of white solidarity as racism itself since he is caused discomfort in negotiating his ties to two significant identity categories; white and Moroccan. This is an experience of racism that a blatantly visible Moroccan person would not encounter. Therefore, in spite of the fact that Najib's optional ethnicity grants him significant privilege, when his Moroccan heritage becomes salient he does indeed experience racism, albeit in a distinctly different form from that of a visibly Moroccan individual.

Najib's experiences of racism in terms of the tension produced by negotiating his whiteness and Moroccanness may be in fact be further compounded by the process of passing itself. Indeed, such conflicts that are experienced as racism because of the act of passing may be illuminated when returning to the example of Najib's tendency to not immediately judge the "Moroccans on the corner of the street". One significant conflict experienced by passers, according to Goffman (1974), arises from the fact that they are "torn between two attachments" (p.109) and therefore experience a sense of disloyalty towards the category from which they have passed. To safeguard the position as a passer, in fact, one is encouraged to refrain from challenging negative sentiments towards their concealed stigmatized category (Goffman, 1974). In light of this layer to the act of passing, Najib's tendency to avoid judgment of the negative stereotypes of Moroccans may be understood to signify his internalization that it is "normal" or acceptable for white Dutch people to perpetuate such stereotypes. Despite his whiteness, Najib feels uncomfortable to engage in these same negative judgments as they represent acts of disloyalty towards his Moroccan heritage and family. The tension that stems from the internalized acceptability of judging the "Moroccans on the corner of the street" is experienced by Najib as racism and, as is the case with the expectation to cover, is distinctly different from that of a visibly Moroccan person. 
"Just a Family": Whiteness as the Human Norm in Dutch Visual

\section{Culture}

A significant portion of the interview with Najib focused on his connection to Dutch visual culture in light of his concentration on performance at a Dutch theatre academy. This aspect of his life was deemed to be of particular importance to the research at hand because of the large impact that his appearance has in both his on-stage performance and racial identity. Moreover, further relevance and significance of Najib's relation to performance emerges from Hondius' (2014) claim that people of color remain "institutionally invisible and inarticulate" (p.274) in Dutch organizations such as the performing arts industry. According to her, these organizations reflect more broadly the dynamics of underrepresentation and overrepresentation of people of color in multiple branches of social interaction and organization in the Netherlands, which is interwoven into the dynamics of passive (in) tolerance of Moroccan culture. Therefore, because of Najib's white appearance, the reflections on his experiences with Dutch visual culture in terms of his race may be connected to these passive forms of racism in the Netherlands that indeed extend beyond the stage or screen and into other realms of social life. To understand Najib's position in relation to Dutch visual culture, I examined this aspect of his identity in terms of both his role as a consumer of Dutch film, theatre and TV and as an actor who performs and will make a career therein.

Najib's depiction of Dutch visual culture indicated the persistence of white supremacy based on the unquestionable assumption that whiteness is the norm for all of humanity, which Sue (2006) terms "the invisible whiteness of being". The position of whiteness as standard, Najib explained, is a particularly salient reality within visual culture in the Netherlands:

In a realistic image, in a movie, if you want to shed light on the image of a family in The Hague, you're probably going to get a white family... So people who go to the movies and see a white family just think "Oh, okay that's just a family". But if people see a Moroccan family, they think "Oh, it's going to be about a crime, or they will go down the wrong path".

The image of the white family as "just a family" provides a categorization of white in Dutch visual culture - and indeed, in the Netherlands - that is supposedly external to and uninfluenced by race. It hints further towards the dominant definition of whiteness as default or standard, as the point of reference for all other races and as the essential quality of the image of Dutch identity (Sue 2006; Essed \& Trienekens 2008). As such, with the Moroccan family defined as Other, it is represented in contrast to the image of a white Dutch family. In essence, the connotations of crime and wrongdoing associated with the Moroccan family are formed through and for the eyes of the dominant white Dutch society. By representing Dutch and Moroccan as a binary of good and bad respectively, the side of Dutch visual culture of which Najib speaks does not deconstruct or discuss, and thereby reinforces, cultural differences; it is this outcome which signifies that this industry is interwoven into the passive forms of (in)tolerance proposed by Hondius (2014). In any case, while visual culture frames whiteness as invisible, default and standard in Dutch society, Moroccan identity is cast to its fringes and becomes abnormal in contrast.

Within this categorization of whiteness as the human norm, Najib occupies a minority privileged position as his appearance allows him to pass as white. He explained that he has been cast in series as the default Dutch young man with blonde hair and blue eyes which therefore provides to him with a number of career opportunities. However, for visibly Moroccan actors, Najib described their casting possibilities quite differently:

It's always something bad: the thief, the bad guy, the dealer... People [of color] in my class who graduate and 
don't have a job, for instance, get called for the role of the criminal and do it because they have to pay their rent and then they end up only playing criminals for the rest of their lives.

The differences in experience in being cast between Najib and visibly Moroccan actors uncover the privileges awarded to him by passing as white in Dutch visual culture. While a visibly Moroccan actor will be forced to play degrading roles in order to earn an income, there are a spectrum of possibilities for Najib precisely because of "the invisible whiteness of being" (Sue, 2006), the idea of the white family as "just a family". Despite dominant claims, the Netherlands is not and cannot be "post-race" as long as such deep inequalities exist between the number and types of roles available for Najib and people of color in his class because of their appearance.

Furthermore, the representation of Moroccan families and individuals as criminals or abnormal is problematic for Najib's connection to the characters he sees on screen or on stage. When considering how Najib consumes Dutch visual culture, the theatrical metaphors used to describe self-presentation by Goffman (1959) mean that his classical work becomes particularly pertinent in this instance. The expressive equipment described by Goffman are employed by individuals to perform their self in a certain way; this constitutes their front. The front may be divided into the scenic - which encompasses the setting - and the personal - which encompasses appearance and manner and which refers to the expected social status and interaction role of the performer herself respectively. With the front providing the tools to present oneself to others, their repetitive assemblage into presentations of Moroccan actors within degrading roles on screen may serve to perform racial scripts that are internalized by the dominant white Dutch audience, according to Robin DiAngelo's (2012) line of reasoning. The influence of white supremacy, therefore, transforms the previously powerless conception of Goffman's
(1959) front into a presentation that has significant racial implications. Interestingly, the perpetuation of white supremacy in the presentations of Moroccan characters in Dutch visual culture has influenced Najib's response to films and television in terms of his racial identity:

I think I feel connected to the Dutch white characters. But that's also because of what we just talked about, that the Moroccan actors are always the thieves or the criminals. So, this is something that I don't connect to because they play these roles. But if they would play the random or normal guy, I think then it would make a difference for me.

Here, Najib explains that his association to Moroccan characters within Dutch visual culture is diminished because they fulfill a negative stereotype which does not reflect his lived experience. Since observers anticipate a consistency between the appearance, manner and setting of an individual, the front of a Moroccan character on screen - as presented as a criminal, for example - may fulfill the expectations of the dominant white Dutch society (Goffman 1959). However, Najib sees a disparity between the front of Moroccan characters presented on stage and his own; he is not a criminal and therefore he cannot relate to the Moroccan character he sees on screen. In this way, Dutch visual culture - and Dutch society, more generally - can be seen to encourage Najib to distance himself from his Moroccan heritage. While associating with the white Dutch characters provides Najib with a sense of belonging in the Netherlands, connection to the Moroccan characters would engender him as outcast, hopeless and problematic. Within the good/bad binary of Dutch and Moroccan stemming from their respective representation, the reinforcement of a definitive and irreconcilable difference between these two categories that is akin to passive (in)tolerance does not provide a space for Najib to position the hybridity of his racial identity. Indeed, even when a hybrid identity has been represented on stage or screen, it is 
most often framed as relentlessly striving towards assuming the image of one of its racial categories, rather than their precise unification (Bolatagici 2004). Therefore, when consuming Dutch visual culture and associating with the represented characters, Najib must make a decision between his ties to both Moroccan and Dutch. In effect, Dutch visual culture encourages quite a predictable decision since Najib can feel normal when and only when he pictures himself purely as a white Dutch person. Racism, in essence, can be seen to persist in Najib's consumption of Dutch visual culture whose assemblage of the expressive tools of Moroccan characters on screen define them as marginalized and undesirable and whitewashes Najib's sense of racial identity.

\section{Conclusion}

Najib's experiences of race and racism are subjective, lived and performed in terms of his minority-privileged position as both white and with a Moroccan heritage. Najib and his hybrid identity are positioned in the Dutch context of discourse, or lack thereof, that renders cultural differences as essential, irreconcilable and thereby allows the supposedly liberal and tolerant Netherlands to picture itself as "postrace". Therefore, Najib effectively negotiates his hybrid racial identity amongst a social, cultural and national environment that denies the unification of the Moroccan and Dutch backgrounds that he embodies. As such, Najib occupies a powerful minority-privileged identity that inherently destabilizes notions of a "postrace" Netherlands, as illustrated by his privileges that stem from his white appearance as well as his experiences of racism that are distinct from those of someone who is visibly Moroccan.

The interview conducted with Najib predominantly uncovered the effects of race in terms of the Dutch national image, racial passing and Dutch visual culture. Essed \& Trienekens (2008) argue that the Dutch image is essentially white, which therefore places Najib on the privileged side of the autochthone/ allochthone binary when being treated by Dutch people. However, Najib experiences racism in response to negative stereotypes of
Moroccans by their visual connection to his family which thereby illuminates the biologically deterministic - and not cultural - foundation on which whiteness in the Dutch national image fundamentally stands. Furthermore, the Goffmanian performative nature of Najib's racial identity allows him to pass as white and gain privilege from concealing his stigma; an ability which he himself labels his "luxury position". Nevertheless, the Arabic root of Najib's name decreases his ability to pass as white as it operates as a racial marker which has caused experiences of racism since he is pictured to not conform to the image of his name. Finally, access to more diverse and respectable roles in Dutch visual culture has been granted to Najib because of his whiteness, in contrast to the people of color in his class who may only play criminals and "bad guys" for the entirety of their careers. It is for this reason that Najib does not associate with the Moroccan characters in Dutch visual culture; they are simply viewed as incongruent to his lived experience. On these three levels, the apparently "post-race" Netherlands can be framed to encourage the suppression of Najib's Moroccan identity with the supplementation of the white Dutch image.

What is clear in the case of Najib is that his experiences with race and racism are distinctly different from both the average white Dutch person and a visibly Moroccan person in the Netherlands. As such, the portrait of Najib's hybrid racial identity extends upon the research of Hondius (2014) which indicates that skin color and appearance are crucial to the shape and persistence of racism in the Netherlands. In fact, by embodying the unification of Dutch and Moroccan which are considered supposedly irreconcilable by forms of passive (in)tolerance in the Netherlands, the essential nature of cultural incompatibility is subverted. As a result, with appearance so central to Najib's racial experience and with the passive (in)tolerance akin to Dutch racism illuminated by his minority -privileged identity, claims to a "post-race" Netherlands are rendered simply illusory and rather generative of racism itself. Indeed, if the "post-race" position of the Netherlands were a reality then Najib would not gain privilege from 
passing as white, nor would he experience racism when his Moroccanness becomes visible. Therefore, providing a portrait of Najib's minority-privileged racial identity has subverted the progressive and "post-race" claims of the Netherlands and has rather emphasized their under-articulated discussion on racism.

In the Netherlands, the categories of white and ethnic minority become mutually exclusive when considering the image of Dutch identity that excludes "non-white" cultures. However, the impossibility of Najib's existence empowers him to deconstruct and challenge discourse of (post-)race and (post-)racism in the Netherlands. Nevertheless, in order to increase the transferability of this ethnographic portrait of Najib's racial identity, more research should be conducted into the nuances of passing as white in the Netherlands as well as the dynamics of whiteness in Dutch visual culture. This may be achieved by conducting interviews with white passers similar to Najib, or people of color who are involved in the performing arts. From this accumulation of research, the more underlying and passive mechanisms of race may be identified and deconstructed on a larger scale. In any case, the portrait of Najib's racial experience uncovers his subversive position within the impossible intersection between whiteness and Moroccan identity which allows him to experience both oppression and privilege; for his racial identity to be both visible, and invisible.

\section{Acknowledgments}

Heartfelt acknowledgements go out to two people. Firstly, to Ulrike Mueller, my sociology teacher at University College Maastricht, for not only her guidance in writing the original assignment which led to this article, but also for her dedicated teaching which has significantly informed my critical sociological lens. Secondly, to Najib, for his willingness to be the subject of this research, and for his acute opinions on whiteness in the Netherlands which pushed my critical views even further. 


\section{References}

Bolatagici, Torika. 2004. Claiming the (N)either/(N)or of 'Third Space': (Re)presenting Hybrid Identity and the Embodiment of Mixed Race. Journal of Intercultural Studies, 25(1): 25-85.

DiAngelo, Robin. 2012. What Does it Mean to be White? Developing White Racial Literacy. New York: Peter Lang Publishing.

Elam, Michele. 2007. “Passing in the Post-Race Era: Danzy Senna, Philip Roth, and Colson Whitehead". African American Review, 41 (4):749-768.

Essed, Philomena. 1996. Diversity: Gender, Color and Culture. Amherst, MA: University of Massachusetts

Essed, Philomena \& Isabel Hoving. 2014. Dutch Racism. Amsterdam: Rodopi

Essed, Philomena \& Sandra Trienekens. 2008. 'Who Wants to Feel White?' Race, Dutch Culture and Contested Identities. Ethnic and Racial Studies, 31(1):52-72.

Fanon, Franz. 1967. Black Skin, White Masks. New York: Grove Press

Gay y Blasco, Paloma. 2010. "The Fragility of Cosmopolitanism: A Biographical Approach." Social Anthropology, 18(4):403-409.

Goffman, Erving. 1974. Stigma: Notes on the Management of Spoiled Identity. Harmondsworth: Penguin Books

Goffman, Erving, 1959. The Presentation of Self in Everyday Life. New York, NY: Anchor Books

Hondius, Dienke. 2014. Black Dutch Voices: Reports from a Country that Leaves Racism Unchallenged. Dutch Racism, 27:273-293. Leiden: Brill

Guba, Egon \& Lincoln, Yvonna. 1981. Effective Evaluation. Jossey-Bass Publishers: San Francisco, CA

Lentin, Alana. 2008. Europe and the Silence about Race. European Journal of Social Theory, 11 (4), 487-503.

doi:10.1177/1368431008097008

Onwuachi-Willig, Angela \& Mario L.Barnes. 2005. By Any Other Name?: On Being "Regarded As" Black, and Why Title VII Should Apply Even If Lakisha and Jamal Are White. UC Davis Legal Research Paper Series. Retrieved 26/6/2016 from: https:// papers.ssrn.com/sol3/papers.cfm?abstract_id $=870048$ 
Pollock, Mica. 2004. Colormute: Race Talk Dilemmas in an American School. Princeton, NJ: Princeton University Press Siebers, Hans \& Dennissen, Marjolein HJ. 2015. Is It Cultural Racism? Discursive Exclusion and Oppression of Migrants in the Netherlands. Current Sociology, 63(3):470-489.

Sue, Derald Wing. 2006. The invisible Whiteness of being: Whiteness, White Supremacy, White Privilege, and Racism. In Addressing Racism: Facilitating Cultural Competence in Mental Health and Educational Setting, edited by Madonna G. Constantine and Derald Wing Sue, 15-30. Hoboken, NJ: John Wiley \& Sons

Stone, Gregory P. 1974. "Appearance and the Self: A Slightly Revised Version*". In Life as Theater: a Dramaturgical Sourcebook, Dennis Brissett and Charles Edgley, eds. Chicago: Aldine

Sundquist, Christian, B. 2012. Signifying on passing: (post) postracialism, (post) post-Marxism and (Post) post-modernism. Columbia Journal of Race and Law, 1(3):482-489.

Waters, Mary, C. 1996. 'Optional Ethnicities: For Whites Only' in Origins and Destinies: Immigration, Race and Ethnicity in America, Sylvia Pedraza and Ruben Rumbaut, eds. 444-454. Belmont, CA: Wadsworth Press, 444-454

Weiner, Melissa F. 2014. The Ideologically Colonized Metropole: Dutch Racism and Racist Denial. Sociology Compass 8(6):731-744. 